\title{
Modulation of paraquat toxicity by $\beta$-carotene at low oxygen partial pressure in chicken embryo fibroblasts
}

\author{
BY SUSAN M. LAWLOR AND NORA M. O'BRIEN* \\ Department of Nutrition, National Food Biotechnology Centre, University College, Cork, Ireland
}

(Received 10 March 1995-Revised 20 May 1996-Accepted 13 June 1996)

\begin{abstract}
The efficiency with which $\beta$-carotene protects against oxidative stress in chicken embryo fibroblasts (CEF) at low $\mathrm{O}_{2}$ partial pressures was assessed. Primary cultures of CEF were grown at low $\mathrm{O}_{2}$ partial pressures and oxidatively stressed by exposure to paraquat (PQ). Activities of the antioxidant enzymes superoxide dismutase (EC 1.15.1.1; SOD), catalase (EC 1.11.1.6; CAT) and glutathione peroxidase ( $E C$ 1.11.1.9; GSH-Px) were measured as indices of oxidative stress. CEF incubated with $0.25-1.0 \mathrm{mM}-P Q$ for $18 \mathrm{~h}$ exhibited increased SOD and CAT activities compared with non-PQ-treated control cells $(P<0 \cdot 001)$. No cytotoxicity as indicated by lactate dehydrogenase $(E C$ 1.1.1.27; LDH) release was observed at PQ concentrations below $2.0 \mathrm{mM}$. Incorporation of added $\beta$-carotene into $0.25 \mathrm{mM}-\mathrm{PQ}$-treated cells prevented the $P Q$-induced increases in SOD and CAT, and activities were similar to those seen in non-PQ-treated control cells. GSH-Px activity decreased relative to its control value on exposure to $0.25 \mathrm{mM}-\mathrm{PQ}$ and $\beta$-carotene prevented this decrease in a dose-dependent manner. The proportion of LDH released from the CEF treated with $\beta$-carotene remained below the control value of $2 \cdot 5 \%$ at all times.
\end{abstract}

$\beta$-Carotene: Oxidative stress: Chicken embryo fibroblasts: Paraquat

Oxidative stress and damage by free radicals to biomolecules have been linked to the pathology of a variety of chronic diseases common in the Western world, particularly cardiovascular disease and cancer. Evidence from epidemiological studies (Ziegler, 1991), experimental animal models (Krinsky, 1989), in vitro cell culture (Bertram et al. 1991) and clinical intervention trials (Garewal et al. 1990) suggests that certain carotenoids may exert a preventive antioxidant role against free-radical action. Most studies have focused on $\beta$ carotene as the active micronutrient. $\beta$-Carotene is an effective quencher of singlet oxygen (Foote \& Denny, 1968). Terao et al. (1980) reported that $\beta$-carotene can prevent singlet oxygen-initiated oxidation of methyl linoleate in cooperation with $\alpha$-tocopherol. Krinsky \& Deneke (1982) demonstrated that carotenoids, including $\beta$-carotene, are capable of inhibiting free-radical-induced oxidation of liposomal lipids. Most of these studies have been conducted at atmospheric $\mathrm{O}_{2}$ partial pressure (150 torr). Burton \& Ingold (1984) monitored the oxidation of methyl linoleate in chlorobenzene at $30^{\circ}$ and demonstrated that $\beta$-carotene was an effective antioxidant at low $\mathrm{O}_{2}$ partial pressure in this model. Palozza \& Krinsky (1991) obtained similar results with azobisisobutyronitrile (AIBN)-induced oxidation of a mixture of lipids isolated from rat liver microsomal membranes. In air (150 torr) $\alpha$ tocopherol was $40-50$ times better than $\beta$-carotene as an antioxidant. However, when the $\mathrm{O}_{2}$ partial pressure was reduced to less than 20 torr the difference in effectiveness between $\alpha$-tocopherol and $\beta$-carotene was decreased by about $40 \%$, confirming the enhanced antioxidant activity of $\beta$-carotene at low $\mathrm{O}_{2}$ pressures. Similarly, Kennedy \& Liebler (1992) 
reported that the antioxidant efficiency of $\beta$-carotene in their liposome model declined at high $\mathrm{O}_{2}$ partial pressure (760 torr) whereas $\beta$-carotene was an effective antioxidant at physiological $\mathrm{O}_{2}$ pressure of 15 torr. Studies at low $\mathrm{O}_{2}$ partial pressure may be physiologically more relevant than studies conducted at atmospheric pressures. Pryor (1991) stated that studies on the antioxidant properties of $\beta$-carotene in an aqueous system at low $\mathrm{O}_{2}$ partial pressure had not been reported, and that such studies should be conducted since most tumours are oxygenated at much lower levels than the in vitro solutions exposed to atmosphere of the air.

We have previously studied the modulatory effect of $\beta$-carotene on paraquat (PQ)induced oxidative stress in a cellular system at atmospheric $\mathrm{O}_{2}$ partial pressure (Lawlor $\&$ O'Brien, 1995). The present communication reports the effects of $\beta$-carotene on PQ-induced oxidative stress in a cellular system at low $\mathrm{O}_{2}$ partial pressure.

\section{MATERIALS AND METHODS}

\section{Materials}

The sources of chemicals and biochemical reagents were as indicated previously (Lawlor \& O'Brien, 1994). All culture media including HAM's F10 medium (with glutamine and phenol red), chicken serum, newborn calf serum and trypsin $(0.25 \%)$ were purchased from GIBCO (Paisley, Strathclyde). $\beta$-Carotene ( $99-100 \%$ pure) was obtained from F. Hoffmann-La Roche, Basel, Switzerland. Solvents were of HPLC grade and used without purification.

\section{Chicken embryo fibroblasts (CEF)}

CEF were prepared from 9-10-d-old embryos (obtained from a local egg producer, Whittaker, Cork, Ireland) by methods described previously (Lawlor \& O'Brien, 1994). The cells were grown in culture medium consisting of HAM's F10 supplemented with penicillin/streptomycin (50 units/ml), tryptose phosphate broth $(3 \mathrm{~g} / \mathrm{l}), 7 \mathrm{mM}-\mathrm{NaHCO}_{3}$ and $20 \mathrm{mM}$-HEPES pH 7.2 to which $24 \mathrm{ml}$ chicken serum $/ 1$ and $100 \mathrm{ml}$ newborn calf serum $/ 1$ were added. CEF were cultured in either a humidified Tri Gas incubator (Jencons Nuaire, Plymouth, Devon) in an atmosphere of $\mathrm{N}_{2}-\mathrm{CO}_{2}$ air (90:5:5) (air being a constant humidified flow of a $\mathrm{N}_{2}-\mathrm{O}_{2}$ mixture) giving an $\mathrm{O}_{2}$ partial pressure of 7.5 torr as calculated from the literature (Krinsky, 1993), or in a humidified incubator (Forma Scientific, Marietta, $\mathrm{OH}, \mathrm{USA}$ ) in an atmosphere of $\mathrm{CO}_{2}$-air (5:95) giving an $\mathrm{O}_{2}$ partial pressure of 150 torr. After 4-5 d of primary culture the cells were collected by trypsin (EC 3.4.21.4) treatment (Bosca et al. 1985) followed by centrifugation (2000 $\mathrm{g}$ for $10 \mathrm{~min}$ ), and resuspended in growth medium consisting of culture medium supplemented with $60 \mathrm{ml}$ newborn calf serum/l. Plastic petri dishes (100 mm diameter) were seeded with $2 \times 10^{6}$ cells in $9 \mathrm{ml}$ culture medium per dish. After $4-5 \mathrm{~d}$ of secondary culture the growth medium was removed and replaced by the same volume of incubation medium $(126 \mathrm{mM}-\mathrm{NaCl}, 14$ $\mathrm{mM}-\mathrm{NaHCO}_{3}, 3.8 \mathrm{mM}-\mathrm{KCl}, 0.9 \mathrm{mM}-\mathrm{Na}_{2} \mathrm{HPO}_{4}, 0.6 \mathrm{mM}-\mathrm{KH}_{2} \mathrm{PO}_{4}, 0.6 \mathrm{mM}-\mathrm{MgSO}_{4}, 0.3$ $\mathrm{mM}-\mathrm{CaCl}_{2}, 5.5 \mathrm{mM}$-glucose, $20 \mathrm{mM}$-HEPES, $\mathrm{pH} \mathrm{7.2)}$. The fibroblasts were then incubated in that medium with or without PQ and $\beta$-carotene for the indicated periods of time.

\section{Incubation of chicken embryo fibroblasts with test compounds}

PQ was dissolved in phosphate-buffered saline (PBS; $100 \mathrm{mM}, \mathrm{pH} 7.45$ ) and added to the incubation medium in the desired concentrations. $\beta$-Carotene was obtained from Hoffman- 
La Roche in sealed ampoules under $\mathrm{N}_{2}$ and stored at $-70^{\circ}$. Before use the purity of $\beta$ carotene was determined by HPLC analysis and was found to be greater than $99 \%$. A stock solution of $\beta$-carotene was prepared in absolute ethanol in a lightproofed vessel and vortexmixed for $30 \mathrm{~min}$. The concentration of the prepared solution was measured spectrophotometrically at $452 \mathrm{~nm}$ before further dilutions (mmolar extinction coefficient $=140 \cdot 8$ ). $\beta$-Carotene was then added at the desired concentrations to the incubation medium. At the end of the experiment the CEF $\beta$-carotene content was measured by HPLC analysis and was found to increase with increasing concentrations of $\beta$-carotene in the incubation medium indicating that $\beta$-carotene was being taken up by the cells as reported previously (Lawlor \& O'Brien, 1995). The final concentration of ethanol in cell cultures was $<10 \mathrm{ml} / 1$. Incubation time with $\mathrm{PQ}$ and $\beta$-carotene was $18 \mathrm{~h}$ at $37^{\circ}$. In these experiments there were two control groups, an ethanol control and a control without ethanol. No differences were seen between the control groups (see Tables 2 and 3). Lactate dehydrogenase ( $E C$ 1.1.1.27; LDH) release was determined in all in vitro preparations, as an index of cytotoxicity, by the method of Vassault (1983). LDH release was expressed as a percentage of the total LDH released from cells treated with Triton X-100 $(100 \mathrm{ml} / \mathrm{l})$.

\section{Cell sonicates and enzyme activity measurement}

The cell sonicates were prepared for enzyme analysis by rapidly aspirating the incubation medium followed by addition of $0.5 \mathrm{ml}$ of the appropriate buffer at $0^{\circ}$ to the cell layer. The cells were removed from the dishes by scraping and placed on ice. The CEF were disrupted by pulse sonication using an MSE Soniprep (Model 150; MSE Scientific, Manor Royal, Crawley, Sussex) at $13 \mathrm{amps} / \mathrm{s}$. All sonications were performed for $20 \mathrm{~s}$ with cells at $4^{\circ}$. The sonicates were centrifuged for $10 \mathrm{~min}$ at $100000 \mathrm{~g}$ (Beckman TL 100 miniultracentrifuge, TLN-100 near-vertical rotor, California, USA) at $4^{\circ}$. Catalase (EC 1.11.1.6; CAT) activity in cell sonicates was determined on the same day as harvesting using the method of Baudhuin et al. (1964). The remaining supernatant fractions were stored overnight at $-20^{\circ}$ until superoxide dismutase (EC 1.15.1.1; SOD) activity determined by the method of McCord \& Fridovich (1969), and glutathione peroxidase (EC 1.11.1.9; GSH-Px) activity by the method of Guenzler et al. (1974) were measured. The enzyme assays are used routinely in our laboratory and typically have a CV of less than $5 \%$. All enzyme activities were expressed as units of enzyme activity/mg protein. Details of the enzymic assays used have been described previously (Lawlor \& O'Brien, 1994). Total protein was determined in each sonicate using the Biorad Microassay (Bradford, 1976) using bovine serum albumin as the standard.

\section{Statistical analysis}

Results are presented as mean values and standard deviations of the means. Data were analysed by one-way ANOVA. Following ANOVA, means were compared by Scheffe test (Snedecor, 1964). The level of statistical significance was taken as $P<0.05$.

\section{RESULTS}

Effect of paraquat on superoxide dismutase and catalase activities at low oxygen partial pressures

CEF were incubated under a low partial pressure of $\mathrm{O}_{2}$ ( 7.5 torr) with $0.25-1.0 \mathrm{mM}$-PQ in the medium for $18 \mathrm{~h}$ to determine the effect on the antioxidant enzymes SOD and CAT. The results indicate that following exposure to $P Q$, total SOD activity increased 
Table 1. Effect of paraquat $(P Q)$ on the activity of the antioxidant enzymes superoxide dismutase (EC 1.15.1.1; SOD) and catalase (EC 1.11.1.6; CAT) (Units $\dagger / m g$ protein) and on release of lactate dehydrogenase (EC 1.1.1.27; $\mathrm{LDH}$ ) (total percentage release $\ddagger$ ) in chicken embryo fibroblasts grown at low oxygen partial pressure $(7.5$ torr $) \S$

(Mean values and standard deviations for four culture dishes incubated simultaneously)

\begin{tabular}{|c|c|c|c|c|c|c|}
\hline \multirow{2}{*}{$\begin{array}{l}\mathrm{PQ} \\
(\mathrm{mM})\end{array}$} & \multicolumn{2}{|c|}{ SOD } & \multicolumn{2}{|c|}{ CAT } & \multicolumn{2}{|c|}{$\mathrm{LDH}$} \\
\hline & Mean & SD & Mean & SD & Mean & SD \\
\hline 0 & 3.76 & 1.45 & 3.99 & 0.61 & $3 \cdot 19$ & 0.05 \\
\hline 0.25 & $13.73^{*}$ & 1.46 & $7.40^{*}$ & 0.40 & 1.98 & 0.10 \\
\hline 0.50 & $10.47^{*}$ & 1.07 & $6.97^{*}$ & 0.73 & 3.68 & 0.14 \\
\hline 1.00 & $13.96^{*}$ & 0.56 & $8 \cdot 25^{*}$ & 0.83 & 3.57 & 0.22 \\
\hline 2.00 & - & - & - & - & $9.40^{*}$ & 0.31 \\
\hline
\end{tabular}

* Mean values were significantly different from those for chicken embryo fibroblasts without $P Q, P<0.05$ (ANOVA and Scheffe test).

$\dagger$ For SOD activity, one unit is defined as the amount of SOD required to inhibit the maximum rate of cytochrome $\mathrm{C}$ reduction by $50 \%$. For CAT activity, one unit is defined as the amount required to remove $1 \mu \mathrm{mol}_{2} \mathrm{O}_{2} / \mathrm{min}$.

$\ddagger \mathrm{LDH}$ activity in the medium was measured and expressed as a percentage of the total LDH released from chicken embryo fibroblasts treated with Triton $\mathrm{X}(100 \mathrm{ml} / \mathrm{l})$.

$\S$ For details of procedures, see pp. 134-135.

Table 2. Effect of $\beta$-carotene on paraquat $(P Q)$-induced modulation of the antioxidant enzymes superoxide dismutase (EC 1.15.1.1; SOD), catalase (EC 1.11.1.6; CAT) and glutathione peroxidase (EC 1.11.1.9; GSH-Px) (Units $\dagger / m g$ protein) and on release of lactate dehydrogenase (1.1.1.27; LDH) (total percentage release $\ddagger$ ) in chicken embryo fibroblasts grown at low oxygen partial pressure $(7.5$ torr $) \S$

(Mean values and standard deviations for four culture dishes incubated simultaneously)

\begin{tabular}{|c|c|c|c|c|c|c|c|c|c|}
\hline \multirow{2}{*}{$\begin{array}{l}\mathrm{PQ} \\
(\mathrm{mM})\end{array}$} & \multirow{2}{*}{$\begin{array}{c}\beta \text {-Carotene } \\
(\mu \mathrm{M})\end{array}$} & \multicolumn{2}{|c|}{ SOD } & \multicolumn{2}{|c|}{ CAT } & \multicolumn{2}{|c|}{ GSH-Px } & \multicolumn{2}{|c|}{ LDH } \\
\hline & & Mean & $\mathrm{SD}$ & Mean & SD & Mean & SD & Mean & SD \\
\hline 0 & $0 \|$ & 7.60 & 1.38 & $3 \cdot 22$ & 0.60 & 9.49 & 1.88 & 2.50 & 0.33 \\
\hline 0 & $0 ๆ$ & 7.42 & 0.60 & 3.36 & 0.71 & $8 \cdot 24$ & 0.93 & 2.37 & 0.45 \\
\hline 0.25 & 2 & $17 \cdot 34^{*}$ & 0.50 & $6 \cdot 57^{*}$ & 0.34 & $3.73^{*}$ & 0.76 & 2.40 & 0.24 \\
\hline 0.25 & 0.01 & 8.72 & 0.42 & $3 \cdot 15$ & 0.38 & $4.68^{*}$ & 0.26 & $0.30^{*}$ & 0.01 \\
\hline 0.25 & 0.05 & $7 \cdot 16$ & 0.30 & 3.00 & 0.85 & $8 \cdot 24$ & 0.32 & $0.58^{*}$ & 0.09 \\
\hline 0.25 & 0.10 & $6 \cdot 35$ & 1.00 & 2.52 & 0.34 & 8.20 & 1.22 & $0.30^{*}$ & 0.01 \\
\hline 0.25 & 1.00 & $5.79^{*}$ & 0.48 & $2 \cdot 38^{*}$ & 0.16 & 9.68 & 0.58 & $0.37^{*}$ & 0.01 \\
\hline 0.25 & $10 \cdot 0$ & $8 \cdot 22$ & 1.26 & $2.47^{*}$ & 0.27 & $12.51^{*}$ & 0.50 & $0.42 *$ & 0.21 \\
\hline
\end{tabular}

* Means values were significantly different from those for chicken embryo fibroblasts with no ethanol, no PQ and no $\beta$-carotene, $P<0.05$ (ANOVA and Scheffe test).

$\dagger$ For SOD activity, one unit is defined as the amount of SOD required to inhibit the maximum rate of cytochrome $\mathrm{C}$ reduction by $50 \%$. For CAT activity, one unit is defined as the amount required to remove $1 \mu \mathrm{mol} \mathrm{H}_{2} \mathrm{O}_{2} / \mathrm{min}$. For GSH-Px activity, one unit is defined as the amount required to oxidize $1 \mathrm{nmol} \mathrm{NADPH} / \mathrm{min}$.

$\ddagger$ LDH activity in the medium was measured and expressed as a percentage of the total LDH released from chicken embryo fibroblasts treated with Triton X $(100 \mathrm{ml} / 1)$.

$\S$ For details of procedures, see pp. 134-135.

$\|$ Control cells incubated with no ethanol, no PQ and no $\beta$-carotene.

ๆ Control cells incubated with ethanol but no PQ and no $\beta$-carotene. 
Table 3. Effect of $\beta$-carotene on paraquat $(P Q)$-induced modulation of the antioxidant enzymes superoxide dismutase (EC 1.15.1.1; SOD), catalase (EC 1.11.1.6; CAT) and glutathione peroxidase (EC 1.11.1.9; GSH-Px) (Units $\dagger / \mathrm{mg}$ protein) and on release of lactate dehydrogenase (EC 1.1.1.27; LDH) (total percentage release $\dagger$ ) in chicken embryo fibroblasts grown at normal oxygen partial pressure (150 torr) $\ddagger$ (Data from Lawlor \& O'Brien, 1995 , presented for comparison purposes)

(Mean values and standard deviations for four culture dishes incubated simultaneously)

\begin{tabular}{|c|c|c|c|c|c|c|c|c|c|}
\hline \multirow{2}{*}{$\begin{array}{l}P Q \\
(\mathrm{mM})\end{array}$} & \multirow{2}{*}{$\begin{array}{c}\beta \text {-Carotene } \\
(\mu \mathrm{M})\end{array}$} & \multicolumn{2}{|c|}{ SOD } & \multicolumn{2}{|c|}{ CAT } & \multicolumn{2}{|c|}{ GSH-Px } & \multicolumn{2}{|c|}{$\mathrm{LDH}$} \\
\hline & & Mean & $\mathrm{SD}$ & Mean & SD & Mean & SD & Mean & SD \\
\hline 0 & $0 \S$ & 8.95 & 0.75 & 4.14 & 0.13 & 7.07 & 1.68 & 2.75 & 0.09 \\
\hline 0 & $0 \|$ & 8.90 & 0.60 & $3 \cdot 35$ & 0.57 & $7 \cdot 20$ & 1.18 & 2.05 & 0.60 \\
\hline 0.25 & 0 & $16 \cdot 31^{*}$ & 0.57 & $10 \cdot 02^{*}$ & 0.72 & $2.59^{*}$ & 0.76 & 2.58 & 0.25 \\
\hline 0.25 & 0.05 & $15 \cdot 10^{*}$ & 0.35 & $7 \cdot 71^{*}$ & 0.37 & 9.08 & 1.20 & nt & nt \\
\hline 0.25 & 0.10 & 9.18 & 0.15 & $6 \cdot 26^{*}$ & 0.25 & 7.44 & 0.95 & 3.30 & $1 \cdot 10$ \\
\hline 0.25 & 1.00 & $10.51^{*}$ & 0.35 & $6.42^{*}$ & 0.15 & 12.75 & $3 \cdot 12$ & 2.75 & 0.09 \\
\hline 0.25 & $10 \cdot 0$ & $19.59^{*}$ & 2.20 & $10 \cdot 27^{*}$ & 0.06 & $5 \cdot 34$ & 0.58 & $4 \cdot 10^{*}$ & 0.65 \\
\hline
\end{tabular}

nt, not tested

* Mean values were significantly different from those for chicken embryo fibroblasts incubated with no ethanol, no $P Q$ and no $\beta$-carotene, $P<0.05$ (ANOVA and Scheffe test).

$\dagger$ For definitions of units, see footnotes to Table 2.

$\ddagger$ Chicken embryo fibroblasts were incubated with or without PQ $(0.25 \mathrm{mM})$ and $0-10 \mu \mathrm{M}-\beta$-carotene for $18 \mathrm{~h}$ at normal $\mathrm{O}_{2}$ partial pressure.

$\S$ Control cells incubated with no ethanol, no PQ and no $\beta$-carotene.

$\|$ Control cells incubated with ethanol but not PQ and no $\beta$-carotene.

significantly $(P<0.001)$ at all levels of PQ tested relative to the control which contained no PQ (Table 1$)$. Similarly CAT activity was significantly $(P<0.001)$ greater than that in controls at all levels of $P Q$ tested. LDH release was measured as an index of cytotoxicity. PQ at concentrations of $0.25-1.0 \mathrm{mM}$ was not toxic for CEF as determined by LDH released into the medium (Table 1). The percentage LDH release was less than $4 \%$ of the total released from Triton X-treated cells. However, when $2.0 \mathrm{mM}-\mathrm{PQ}$ was added to the cells the percentage total cellular LDH released increased significantly to $9.5 \%$ $(P<0.001)$ after $18 \mathrm{~h}$ incubation. In subsequent studies $0.25 \mathrm{mM}$-PQ was used to indicate oxidative stress as this level of PQ caused an increase in SOD and CAT activities without causing cytotoxicity.

We previously reported (Lawlor \& O'Brien, 1994) that $0.25 \mathrm{mM}-\mathrm{PQ}$ was also sufficient to increase significantly the activity of the antioxidant enzymes SOD and CAT in CEF cultured in an atmosphere of $\mathrm{CO}_{2}$-air (5:95) without causing cytotoxicity.

\section{Modulation of oxidative stress by $\beta$-carotene at low oxygen partial pressure}

Having established an appropriate in vitro model system at low $\mathrm{O}_{2}$ partial pressure, we tested the potential of added $\beta$-carotene to combat the effects of PQ-induced oxidative stress. CEF were incubated with $0.25 \mathrm{mM}$-PQ and $\beta$-carotene $(0-10 \mu \mathrm{M})$ in the medium for $18 \mathrm{~h}$. The incorporation of $\beta$-carotene into the PQ-treated cells inhibited the increase in SOD activity (Table 2). At all levels of $\beta$-carotene tested, SOD activity was not significantly different $(P<0.05)$ from the control value with the exception of CEF treated with $1.0 \mu \mathrm{M}-\beta$-carotene $(P=0.047)$. SOD activity in this group of cells was lower than in the non-PQ-treated control cells. In contrast, following exposure of cells grown in an atmosphere of $\mathrm{CO}_{2}$-air (5:95) $\left(\mathrm{O}_{2}\right.$ partial pressure of 150 torr) to $\mathrm{PQ}$ and high 
concentrations of $\beta$-carotene $(10 \mu \mathrm{M}), \beta$-carotene had no effect on the PQ-induced increase in SOD (Table 3 and Lawlor \& O'Brien, 1995).

Similar trends were observed when CAT activity was determined. $\beta$-Carotene $(1 \cdot 0-10$ $\mu \mathrm{M})$ inhibited the PQ-induced increase in CAT activity in cells grown under conditions of low $\mathrm{O}_{2}$ partial pressure (7.5 torr) to below that observed in non-PQ-treated controls (Table 2 ). However, the CAT activity significantly increased in cells exposed to $P Q$ and high concentrations of $\beta$-carotene $(10 \mu \mathrm{M})$ when cultured at an $\mathrm{O}_{2}$ partial pressure of 150 torr (Table 3 and Lawlor \& O'Brien, 1995).

GSH-Px activity is inhibited by PQ (Stevens et al. 1988; Lawlor \& O'Brien, 1994). $\beta$ Carotene prevented the decrease in GSH-Px activity in a dose-dependent manner and, at $\beta$ carotene levels of $0.05-1.0 \mu \mathrm{M}$, was not significantly different $(P<0.05)$ from the non-PQtreated control cells grown under low $\mathrm{O}_{2}$ partial pressure (Table 2). $\beta$-Carotene at a level of $10 \mu \mathrm{M}$ increased GSH-Px activity significantly $(P=0.017)$ above the control value (Table 2 ). In contrast, GSH-Px activity tended to be reduced relative to its control value at levels of $10 \mu \mathrm{M}-\beta$-carotene in cells grown at $\mathrm{O}_{2}$ partial pressure of 150 torr (Table 3 and Lawlor \& O'Brien, 1995).

LDH release remained below $2.5 \%$ at all times in cells grown at low $\mathrm{O}_{2}$ partial pressure (Table 2). $\beta$-Carotene supplementation resulted in a further decrease in LDH release. However, percentage $\mathrm{LDH}$ release increased significantly in PQ-treated cells exposed to $10 \mu \mathrm{M}$ - $\beta$-carotene cultured at an $\mathrm{O}_{2}$ partial pressure of 150 torr (Table 3 and Lawlor \& O’Brien, 1995).

\section{DISCUSSION}

Using CEF we developed a model to investigate the effect of PQ-induced oxidative stress on the antioxidant enzymes SOD, CAT and GSH-Px under conditions of low $\mathrm{O}_{2}$ partial pressure. The modulation of PQ-induced oxidative stress by $\beta$-carotene under low $\mathrm{O}_{2}$ partial pressure ( 7.5 torr) was examined and compared with that obtained under atmospheric partial pressure of $\mathrm{O}_{2}$ (150 torr).

PQ acts as a pro-oxidant in our model. The pro-oxidant activity is indicated by the induction of elevated levels of antioxidant enzymes (CAT, SOD) in PQ-treated cells compared with controls (Table 1). PQ generates oxygen free-radicals, including superoxide $\left(\mathrm{O}_{2}^{-}\right.$, Bus et al. 1974), and has been shown to induce antioxidant enzyme activity both in vivo and in vitro (Deneke \& Fanburg, 1980; Stevens et al. 1988; Krall et al. 1991; Lawlor \& O'Brien, 1994). Induction of SOD activity by PQ has been previously reported in Chinese hamster ovary cells (Nicotera et al. 1985), human gingival fibroblasts (Stevens et al. 1988) and PQ-resistant HeLa cells (Krall et al. 1991). CAT is inhibited by $\mathrm{O}_{2}^{-}$in isolated enzyme systems (Kono \& Fridovich, 1982) but not cell cultures. Stevens et al. (1988) found that CAT activity increased at $1.0 \mathrm{mM}-\mathrm{PQ}$ and above in human gingival fibroblasts. CAT activity also increased in PQ-resistant HeLa cells on exposure to $90 \mathrm{mM}$ PQ (Krall et al. 1991). It is thought that CAT is protected from $\mathrm{O}_{2}^{-}$by its location within the peroxisome in cells.

In contrast, a reduction in GSH-Px activity by PQ has been reported in human gingival fibroblasts (Stevens et al. 1988) and in CEF (Lawlor \& O'Brien, 1994). Similarly, in the present study, $0.25 \mathrm{mM}-\mathrm{PQ}$ significantly reduced GSH-Px activity compared with control (Tables 2 and 3). Therefore, PQ does not affect the antioxidant enzymes in a similar manner, i.e. it induces SOD and CAT activities and inhibits GSH-Px activity (Tables 1, 2 and 3). 
The activities of SOD and CAT in CEF grown at low $\mathrm{O}_{2}$ partial pressure ( 7.5 torr) and treated with varying levels of $P Q$ were similar to those previously reported at normal $\mathrm{O}_{2}$ partial pressures (150 torr, Lawlor \& O'Brien, 1994). A level of 0.25 mM-PQ was found in both cases to be the optimal concentration of PQ to induce enzyme activities without causing cytotoxicity (Table 1 and Lawlor \& O'Brien, 1994). In the presence of $\beta$-carotene, however, the PQ induction (SOD, CAT) or inhibition (GSH-Px) of antioxidant enzyme activity was less pronounced suggesting that $\beta$-carotene suppresses the pro-oxidant effects of PQ (Table 2).

The modulatory effects of $\beta$-carotene on PQ-induced oxidative stress in CEF grown in atmospheric $\mathrm{O}_{2}$ partial pressure is shown in Table 3 (Lawlor \& O'Brien, 1995). $\beta$-Carotene at low concentrations $(0.1-1.0 \mu \mathrm{M})$ prevented the PQ-induced elevation of CAT and SOD activities and protected GSH-Px activity. However, at higher concentrations of $\beta$-carotene $(10 \mu \mathrm{M})$ the activities of the antioxidant enzymes were similar to those in the PQ-treated cells without the presence of $\beta$-carotene (Table 3). $\beta$-Carotene at the higher concentrations $(10 \mu \mathrm{M})$ no longer appeared to be effective in modulating the effects of PQ.

In contrast, under conditions of low $\mathrm{O}_{2}$ partial pressure $\beta$-carotene at the higher concentrations tested $(10 \mu \mathrm{M})$ did prevent the induction of SOD and CAT and inhibition of GSH-Px activities by PQ. In addition, $\beta$-carotene was more effective in protecting the antioxidant enzymes against PQ at lower concentrations $(0.01-0.1 \mu \mathrm{M})$ under conditions of low $\mathrm{O}_{2}$ pressure ( 7.5 torr, Table 2) than at atmospheric pressure of $\mathrm{O}_{2}$ (Table 3).

In our model, therefore, the modulation of PQ-induced alterations in antioxidant enzyme activities by $\beta$-carotene varied under different partial pressures of $\mathrm{O}_{2}$. This effect of $\mathrm{O}_{2}$ tension on the behaviour of $\beta$-carotene has previously been reported in other in vitro model systems including liposomal lipids (Krinsky \& Deneke, 1982), homogenous solutions (Stocker et al. 1987; Burton, 1989), and rat liver microsome (Palozza \& Krinsky, 1991). Burton \& Ingold (1984) observed that at a low $\mathrm{O}_{2}$ partial pressure (15 torr) $\beta$ carotene was an effective antioxidant inhibiting the AIBN-induced oxidation of methyl linoleate. However, at high $\mathrm{O}_{2}$ tensions (760 torr) $\beta$-carotene was almost without effect on the rates of auto-oxidation of methyl linoleate. Similar results were obtained by Palozza \& Krinsky (1991) as outlined earlier.

Studies of the behaviour of other carotenoids at low $\mathrm{O}_{2}$ partial pressures in cellular model systems will be continued in future research as suggested by Pryor (1991). These studies are essential to determine how carotenoids function under physiological conditions and to provide an insight into their mechanism of action.

\section{REFERENCES}

Baudhuin, P., Beaufay, H., Rahman-Li, Y., Sellinger, O. Z., Wattiaux, R., Jacques, P. \& deDuve, C. (1964). Tissue fractionation studies. Intracellular distribution of monoamine oxidase, aspartate aminotransferase, $\mathrm{D}$ aminoacid oxidase and catalase in rat liver tissue. Biochemical Journal 92, 179-184.

Betram, J. S., Pung, A., Churley, M., Kappock, T. J., Wilkens, L. R. \& Cooney, R. V. (1991). Diverse carotenoids protect from chemically-induced neoplastic transformation. Carcinogenesis 12, 671-678.

Bosca, L., Rousseau, G. G. \& Hue, L. (1985). Phorbol 12-myristate 13-acetate and insulin increase the concentration of fructose-2,6-bisphosphate and stimulate glycolysis in chicken embryo fibroblasts. Proceedings of the National Academy of Sciences USA 82, 6440-6444.

Bradford, M. M. (1976). A rapid and sensitive method for the quantitation of microgram quantities of protein utilizing the principle of protein-dye binding. Analytical Biochemistry 72, 248-254.

Burton, G. W. (1989). Antioxidant function of carotenoids. Journal of Nutrition 119, 109-111.

Burton, G. W. \& Ingold, K. U. (1984). $\beta$-Carotene: an unusual type of lipid antioxidant. Science 224, $569-573$. 
Bus, J. S., Auat, S. D. \& Gibson, J. E. (1974). Superoxide and singlet oxygen-catalyzed lipid peroxidation as a possible mechanism for paraquat (methyl viologen) toxicity. Biochemical and Biophysical Research Communications 58, 749-755.

Deneke, S. M., \& Fanburg, B. L. (1980). Normobaric oxygen toxicity of the lung. New England Journal of Medicine 303, 76-86.

Foote, C. S., \& Denny, R. W. (1968). Chemistry of singlet oxygen. VII. Quenching by $\beta$-carotene. Journal of the American Chemical Society 90, 6233-6235.

Garewal, H. S., Meyskens, F. L. Jr, Killen, D., Reeves, D., Kiersch, T. A., Elletson, H., Strasbert, A., King, D. \& Steinbronn, K. (1990). Response of oral leucoplakia to $\beta$-carotene. Journal of Clinical Oncology 8, 17151720.

Guenzler, W. A., Kremers, H. \& Flohe, L. (1974). An improved coupled test procedure for glutathione peroxidase in blood. Zeitschrift für Klinische Chemie und Klinische Biochemie 12, 444-448.

Kennedy, T. A. \& Liebler, D. C. (1992). Peroxyl radical scavenging by $\beta$-carotene in lipid bilayers. Effect of oxygen partial pressure. Journal of Biological Chemistry 267, 4658-4663.

Kono, Y. \& Fridovich, I. (1982). Superoxide radical inhibits catalase. Journal of Biological Chemistry 257, 5751-5754.

Krall, J., Speranza, M. J. \& Lynch, R. E. (1991). Paraquat-resistant Hela Cells: increased cellular content of glutathione peroxidase. Archives of Biochemistry and Biophysics 286, 311-315.

Krinksy, N. I. (1989). Carotenoids and cancer in animal models. Journal of Nutrition 119, 123-126.

Krinksy, N. I. (1993). Actions of carotenoids in biological systems. Annual Review of Nutrition 13, $561-587$.

Krinksy, N. I. \& Deneke, S. M. (1982). Interaction of oxygen and oxy-radicals with carotenoids. Journal of the National Cancer Institute 69, 205-210.

Lawlor, S. M. \& O'Brien, N. M. (1994). Development of an in vitro cell culture model to investigate the induction and quantification of oxidative stress and its inhibition by $\alpha$-tocopherol. Toxicology In Vitro 8, 6773.

Lawlor, S. M. \& O'Brien, N. M. (1995). Modulation of oxidative stress by $\beta$-carotene in chicken embryo fibroblasts. British Journal of Nutrition 73, 841-850.

McCord, J. M. \& Fridovich, I. (1969). Superoxide dismutase: an enzyme function for erythrocuprein (hemocuprein). Journal of Biological Chemistry 244, 6049-6055.

Nicotera, T. M., Block, A. W., Gibas, Z. \& Sandberg, A. A. (1985). Induction of superoxide dismutase, chromosomal aberrations and sister-chromatid exhanges by paraquat in Chinese hamster fibroblasts. Mutation Research 151, 263-268.

Palozza, P. \& Krinsky, N. I. (1991). The inhibition of radical-initiated peroxidation of microsomal lipids by both $\alpha$-tocopherol and $\beta$-carotene. Free Radicals in Biology and Medicine 11, 407-414.

Pryor, W. A. (1991). The antioxidant nutrients and disease prevention - what do we know and what do we need to find out? American Journal of Clinical Nutrition 53, 391S-393S.

Snedecor, G. W. (1964). Sampling from a normally distributed population. In Statistical Methods, p. 45 [G. W. Snedecor and W. G. Cochran, editors]. Ames, IA: Iowa State University Press.

Stevens, T. M., Boswell, G. A. Jr, Adler, R., Ackerman, N. R. \& Kerr, J. S. (1988). Induction of antioxidant enzyme activities by a phenyl urea derivative, EDU. Toxicology and Applied Pharmacology 96, 133-142.

Stocker, R., Yamamoto, Y., McDonagh, A. F., Glazer, A. N. \& Ames, B. N. (1987). Bilirubin is an antioxidant of possible physiological importance. Science 235, 1043-1046.

Terao, J., Yamauchi, R., Murakami, H. \& Matsushita, S. (1980). Inhibitory effects of tocopherols and $\beta$-carotene on singlet-oxygen initiated photo-oxidation of methyl linoleate and soyabean oil. Journal of Food Processing and Preservation 4, 79-83.

Vassault, A. (1983). Lactate dehydrogenase. In Methods of Enzymatic Analysis, pp. 118-126 [H. U. Bergmeyer, editor]. Weinheim, Germany: Verlag Chemie.

Ziegler, R. G. (1991). Vegetables, fruits and carotenoids and the risk of cancer. American Journal of Clinical Nutrition 53, 251S-259S. 